\title{
Sugarcane Bagasse-Derived Activated Carbon- (AC-) Epoxy Vitrimer Biocomposite: Thermomechanical and Self- Healing Performance
}

\author{
Balaji Krishnakumar $\mathbb{D}^{1},{ }^{1}$ Debajyoti Bose $\mathbb{D}^{2},{ }^{2}$ Manjeet Singh $\mathbb{D},{ }^{1,3}$ \\ R. V. Siva Prasanna Sanka $\mathbb{D}^{4}{ }^{4}$ Velidi V. S. S. Gurunadh $\mathbb{D}^{1}{ }^{1}$ Shailey Singhal ${ }^{D}{ }^{1}$ \\ Vijay Parthasarthy $\mathbb{D}^{1},{ }^{1}$ Liberata Guadagno $\mathbb{D}^{5},{ }^{5}$ Poornima Vijayan $P \mathbb{D}^{6},{ }^{6}$ Sabu Thomas $\mathbb{D},{ }^{7,8,9}$ \\ and Sravendra Rana ${ }^{1}{ }^{1}$ \\ ${ }^{1}$ University of Petroleum \& Energy Studies (UPES), School of Engineering, Energy Acres, Bidholi, Dehradun 248007, India \\ ${ }^{2}$ Faculty of Applied Sciences \& Biotechnology, Shoolini University of Biotechnology \& Management Sciences, Solan 173229, \\ Himachal Pradesh, India \\ ${ }^{3}$ Department of Chemistry, School of Physical Sciences, Mizoram University, Aizawl, 796004, Mizoram, India \\ ${ }^{4}$ Department of Mechanical Engineering, University Institute of Engineering, Chandigarh University, Gharuan, Punjab 140413, India \\ ${ }^{5}$ Department of Industrial Engineering, University of Salerno, Via Giovanni Paolo II, 132, 84084 Fisciano, Italy \\ ${ }^{6}$ Sree Narayana College for Women (Affiliated to University of Kerala), 691001, Kollam, Kerala, India \\ ${ }^{7}$ International and Inter University Centre for Nanoscience and Nanotechnology, Mahatma Gandhi University, Kottayam, \\ Kerala, India \\ ${ }^{8}$ School of Chemical Sciences, Mahatma Gandhi University, Kottayam, Kerala, India \\ ${ }^{9}$ School of Energy Materials, Mahatma Gandhi University, Kottayam, Kerala, India
}

Correspondence should be addressed to Liberata Guadagno; lguadagno@unisa.it and Sravendra Rana; srana@ddn.upes.ac.in

Received 21 January 2021; Revised 25 March 2021; Accepted 2 June 2021; Published 15 June 2021

Academic Editor: Peng He

Copyright (c) 2021 Balaji Krishnakumar et al. This is an open access article distributed under the Creative Commons Attribution License, which permits unrestricted use, distribution, and reproduction in any medium, provided the original work is properly cited.

\begin{abstract}
Vitrimeric materials have emerged as fascinating and sustainable materials owing to their malleability, reprocessability, and recyclability. Sustainable vitrimeric materials can be prepared by reinforcing polymeric matrix with bioderived fillers. In the current work, a sustainable vitrimer is prepared by incorporating biomass-derived activated carbon (AC) filler into the epoxy matrix to achieve enhanced thermal and mechanical properties. Thus, prepared biocomposite vitrimers demonstrate a lowertemperature self-healing $\left(70^{\circ} \mathrm{C}\right.$ for $\left.5 \mathrm{~min}\right)$ via disulfide exchanges, compared to the pristine epoxy vitrimers $\left(80^{\circ} \mathrm{C}\right.$ for $\left.5 \mathrm{~min}\right)$. Significantly, the self-healing performances have been studied extensively with the flexural studies; and changes in material healing efficiency have been demonstrated based on the observed changes in modulus.
\end{abstract}

\section{Introduction}

Conventional thermosetting polymers have been applied in various fields like automobile, construction, aviation, wind turbines, and coatings [1]. The last decade has witnessed exciting progress concerning the design and development of structural polymeric materials, necessary to keep up with the challenging tasks that scientists all over the world have to face for the future. Although many thermosetting composites have been effectively designed to ensure good mechanical performance and self-responsive ability [2-5], the usage of thermoset material is restricted due to their poor reusability and reprocessability. This is due to their extremely high crosslink density, which restricts chain exchanges and therefore decreases malleable nature. On account of this, adequate research on malleable thermoset materials has been carried 
out in the last few years [6]. Previously reported reprocessable thermosets via Diels-Alder chemistry have demonstrated (dissociative covalent adaptive network) their exchanges in a disruptive way, wherein network crosslink density has changed abruptly [7]. In 2011, Montarnal and coworkers [8] introduced reprocessable thermoset "vitrimer," which extended the existing classification, as well as entailed fixed crosslink density via exchangeable covalent adaptive network formations. Owing to fixed network integrity, vitrimer materials behave like a silica glass former. Depending on the temperature range, they can also manifest the behavior of a viscoelastic fluid. They are characterized by a special viscoelasticity regime, which denotes a topology freezing-point temperature $\left(T_{\mathrm{v}}\right)$, which can be situated below or above the glass transition temperature $\left(T_{\mathrm{g}}\right)$. Also, the established $T_{\mathrm{v}}$ has been extrapolated through Arrhenius and Maxwell equations; hence, it was measured after viscosity reaches $10^{12} \mathrm{~Pa} \cdot \mathrm{s}$ [8].

Moreover, many thermoset vitrimers have been introduced with different chemistries like transesterification [9], transcarbomylation [10], transamination [11], disulfide linkages [12], and imine exchanges [6]. Transesterification-based vitrimer system has been majorly discussed (with or without catalyst), due to their simple preparation and effective covalent exchange mechanism [13-15]. The reported malleable thermoset vitrimers are all recyclable/reprocessable, and some of them have exhibited self-healing performances. Vitrimers having intrinsic self-healing are more attractive than those based on extrinsic self-healing mechanisms in which the healing can be activated via covalent network exchanges [16]. In particular, low-temperature self-healing demonstrated disulfide exchange-assisted vitrimer materials which have been reported adequately, to acquire the processable vitrimer system with intrinsic self-healing properties [17, 18]. Further, the different chemistry involvement encourages the vitrimer material with prevailed properties for a real-time application (such as soft electronics, 3D printing, and adhesives) [19, 20].

Since the development of vitrimer studies, various kinds of fillers have been incorporated in epoxy/vitrimeric matrices, where better thermal and mechanical properties were achieved with effect of nanofiller addition. In particular, the addition of carbon allotrope-based fillers in a vitrimeric system resulted in prominent mechanical and self-healing properties [21]. In recent times, bioderived monomers have been included in vitrimer studies to prepare sustainable vitrimer materials [15, 22-24], where like sustainable bio-based polymers have gained huge interest to aspire the green environment [25]. Bio-based vitrimers have been developed from different derivatives like lignin, fructose, and soybean oil [26]. However, their thermal and mechanical performances were found to be comparatively lower than the synthetically prepared vitrimeric materials. To overcome these weaknesses, the addition of fillers into the matrix has been realized and exhibited notable sustainability and improved thermal/mechanical properties. Recently, bio-based epoxy/cashew nutshell liquid vitrimer was demonstrated with CNTs, where the inclusion of CNT in the vitrimer was helpful to acclaim NIR light/low-temperature shape recovery and transesterification exchanges. Significantly, an addition of $0.3 \mathrm{wt} \% \mathrm{CNT}$ resulted in a prominent shape memory via thermal (at $60^{\circ} \mathrm{C}$ ) and near-infrared (NIR) light [27]. Furthermore, transcarbonation exchange-promoted vitrimers were studied with cellulose paper, where the paper has introduced hydrogen bonds with polycarbonate covalent bonds. Also, the performed vitrimer composite described the prudent selfhealing and shape memory properties [28].

In addition to achieve more sustainable composites, sugarcane bagasse-derived activated carbon/bio-based fillers have been unified in an epoxy vitrimer system to achieve a lowtemperature self-healing material (via the reduction of $T_{g}$ ). Inquisitively, sugarcane bagasse-derived activated carbon(AC-) epoxy vitrimer biocomposites including their thermomechanical and self-healing properties have not been explored yet. In the effort to prepare sustainable bio-based vitrimers, biofiller involvement in vitrimers has been of great demand and required much attention by the researchers; thus, herein, we present an epoxy vitrimer biocomposite sugarcane bagassederived chemically activated carbon (AC) as biofiller. Owing to this, the biocomposite vitrimer is designed with aromatic disulfide crosslink-assisted self-healing; also, different concentrations of AC are used to optimize chemical and mechanical properties of epoxy vitrimer biocomposites. The influence of AC on the glass transition temperature $\left(T_{g}\right)$ of the matrix has also been studied. The self-healing efficiency (based on a covalently adaptive network) through flexural studies and active carbon dependent changes on healing and thermomechanical performances have been eloquently addressed.

\section{Experimental Section}

2.1. Material and Methods. Bisphenol A diglycidyl ether (BADGE) (340.41 g/mol) resin, $40 \mathrm{wt} \%$ phosphoric acid (BDH grade), and 2-aminophenyl disulfide (AFD) (248.37 $\mathrm{g} / \mathrm{mol}$ ) hardener were used as received from Sigma-Aldrich.

2.2. Preparation of Epoxy Vitrimer Biocomposites. Activated carbon was prepared from sugarcane refuses, based on the literature (supporting information (SI) (available here)) [29]. The prepared AC was dispersed in ethanol (150 mg in $10 \mathrm{~mL}$ ) via ultrasonication for $30 \mathrm{~min}$. Subsequently, finely dispersed activated carbon in different loadings (EP-x\%; $\mathrm{x}-0$ (p-pristine), 0.1, 0.2, 0.5, 1, and 2) was added in BADGE resin and heated at $80^{\circ} \mathrm{C}$ under vacuum condition till ethanol evaporation. Thereafter, a stoichiometric ratio of hardener 2-aminophenyl disulfide (AFD) was added and stirred at the same temperature for $15 \mathrm{~min}$. Finally, the degassed mixture was kept in a silicon mold and cured at $150^{\circ} \mathrm{C}$ for $5 \mathrm{~h}$.

\subsection{Preparation of Conventional Thermoset Epoxy} Biocomposite. To evaluate the effect of AFD incorporation onto self-healing properties, AFD free activated carbonbased conventional thermoset epoxy biocomposites were also prepared. Activated carbon-dispersed ethanol solution was added in BADGE $(500 \mathrm{mg}, 1.47 \mathrm{mmol})$ resin at $80^{\circ} \mathrm{C}$ temperature with stirring. After evaporation of ethanol, weighed DETA $(60 \mathrm{mg}, 0.5 \mathrm{mmol})$ was added and stirred at $40^{\circ} \mathrm{C}$ for $15 \mathrm{~min}$. Then, the mixture was poured in a silicon mold 

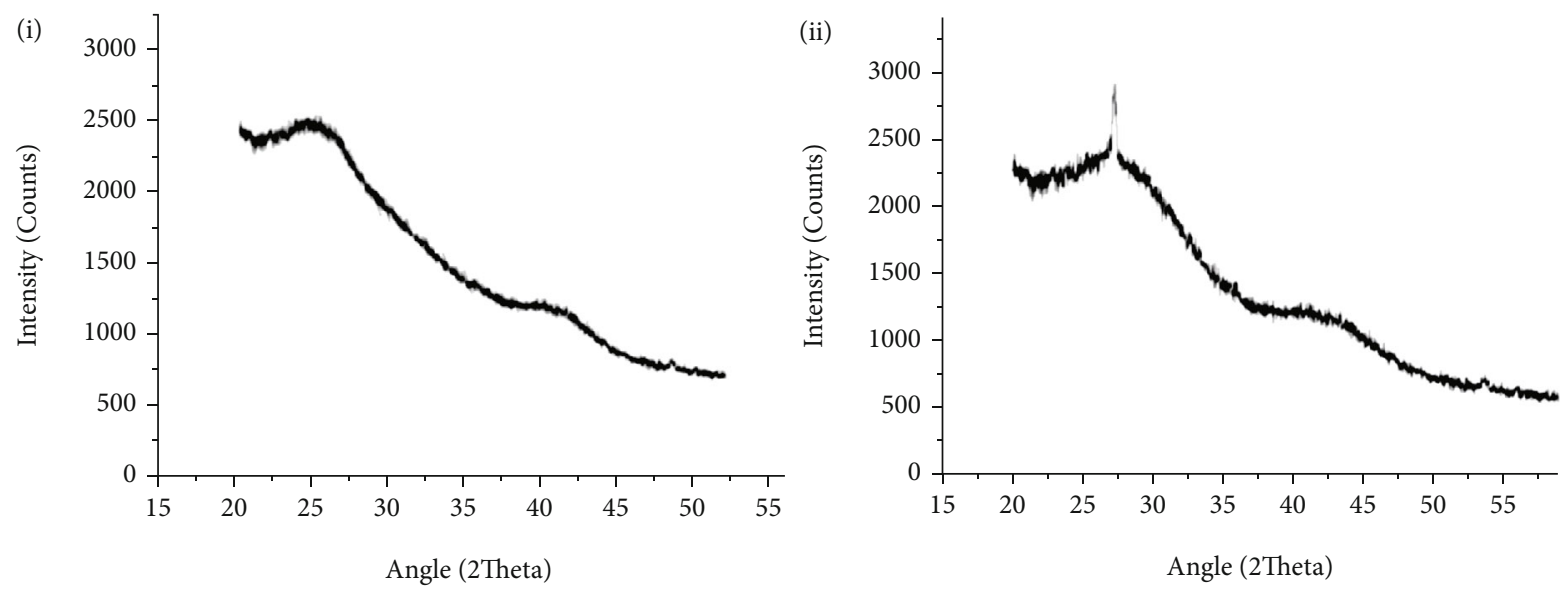

(a)

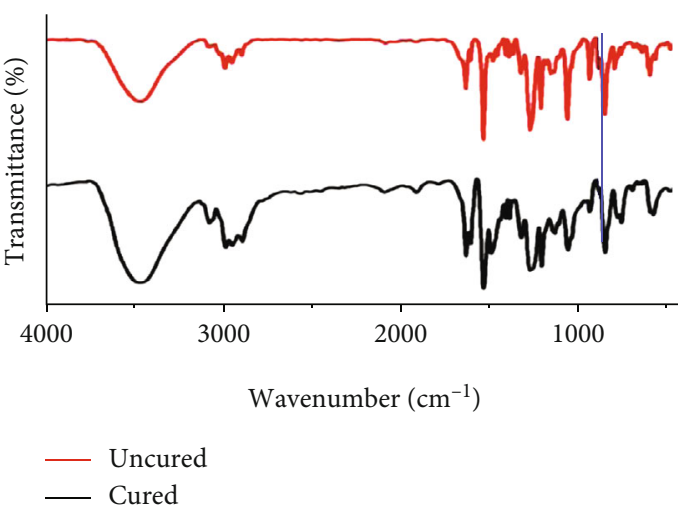

(b)

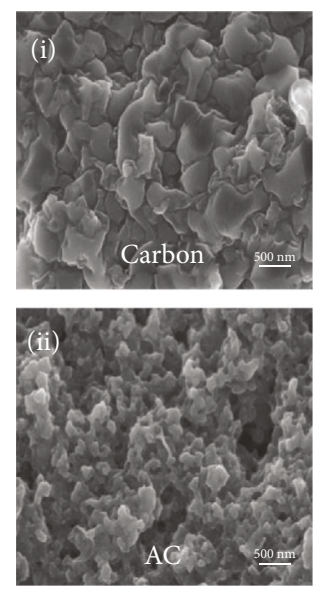

(c)

FIGURE 1: (a) XRD pattern of activated carbon (AC). (b) FT-IR spectra for uncured and cured epoxy. (c) SEM images for biomass-derived (i) carbon and (ii) activated carbon.

and kept at room temperature for $24 \mathrm{~h}$. The obtained specimens were involved in different studies.

2.4. Characterization Techniques. X-ray diffraction spectroscopy was analyzed through D8 ADVANCE ECO-Bruker to identify the activated carbon. Scanning electron microscopy (SEM; Quanta FEG 200) analysis was used to observe the surface of activated carbon. The epoxy curing was observed through FT-IR (Frontier FT-IR/FIR, PerkinElmer) spectra analysis. $T_{\mathrm{g}}$ was characterized using thermomechanical analyzer (TA-Q400 EM) dimensional change experiments. In TA-Q400 EM, a three-point bending test was performed to address the storage modulus, loss modulus, stress relaxation, and stress-strain behavior of the rectangular specimens $(15 \times 5 \times 0.5 \mathrm{~mm})$. All dimensional change, storage modulus, and loss modulus experiments were performed through temperature ranges from $40^{\circ} \mathrm{C}$ to $120^{\circ} \mathrm{C}$ using heating rates of $10^{\circ} \mathrm{C} / \mathrm{min}$ with $50 \mathrm{~mL} / \mathrm{min}$ nitrogen purge gas flow and $0.02 \mathrm{~N}$ force. In the stress relaxation study, $1 \times 10^{-3} \mathrm{~N}$ preloaded force was applied to straighten the specimen. During the test, the required temperature and $1 \%$ strain were applied, and then, relaxation modulus was evaluated with respect to time. Stress-strain experiments were performed in strain ramp mode with $0.02 \mathrm{~N}$ force and evaluated strain at $40^{\circ} \mathrm{C}$ isothermal temperature.

\section{Results and Discussions}

3.1. Material Characterization. Biomass-derived carbon and AC were investigated by XRD analysis to identify their formation from biomass (Figure 1(a), (i) and (ii)). The performed XRD for biomass-derived carbon has resulted in a broad peak around $26^{\circ}$, where the absence of sharp peaks denoted the amorphous structure. Subsequently, the performed AC exhibited that narrow peaks have indicated the regularity of crystalline structure and layer integral formation with adequate surface volume [30, 31]. Altogether, the observed peak at $26.27^{\circ}$ is a characteristic of graphite flake-like hexagonal structure, and therefore, AC can also be termed as assemblies of defective graphene [21]. Thus, the chemically activated carbon (comprised of graphite and $\pi$ electron-connected graphene layer) exhibits an intense porosity, which has an increase in surface area, despite that it deforms the graphene layer structure [32, 33]. SEM analysis shows the sugarcane bagassederived carbon and activated carbon surface, in which chemically (phosphoric acid) activated carbon highlights pores on its 
TABLE 1: Glass transition temperature of epoxy nanocomposites.

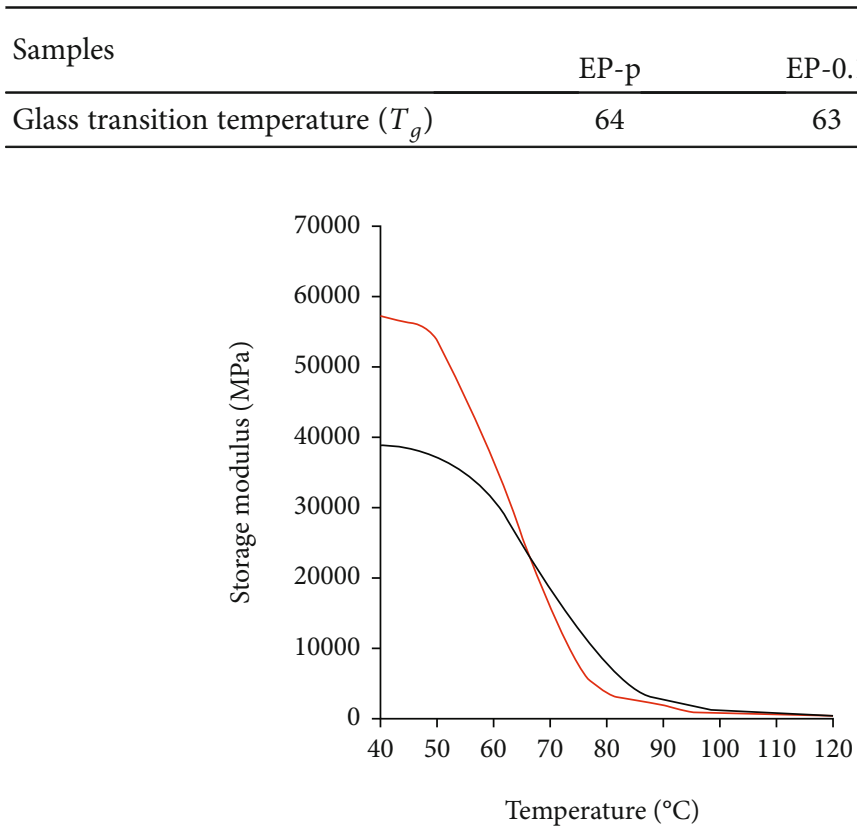

(a)

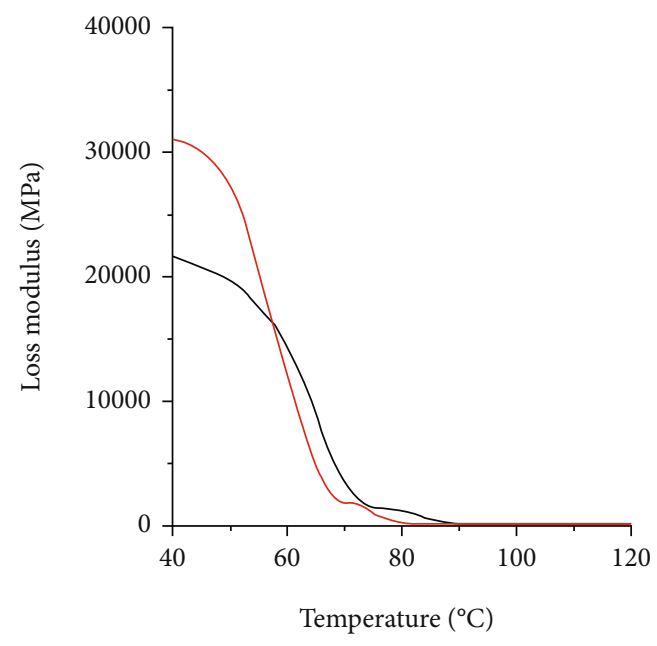

(b)

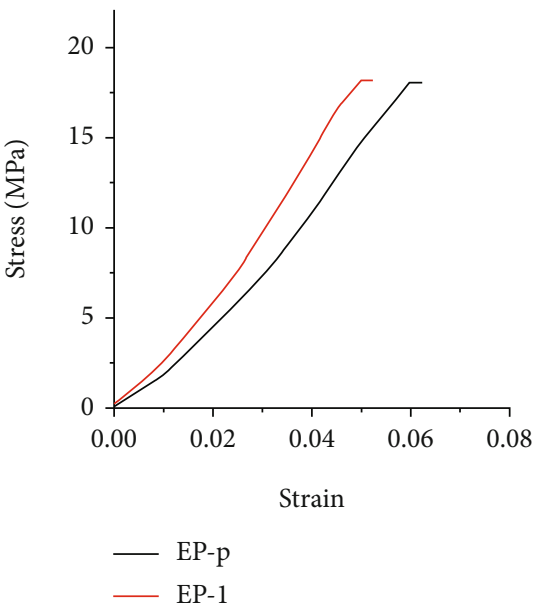

(c)

Figure 2: (a) Storage modulus, (b) loss modulus, and (c) flexural stress-strain curve for epoxy and biocomposite vitrimers.

surface (Figure 1(c), (i) and (ii)). These low-volume pores confer to AC the capability to extend the surface area for chemical reactions and are helpful to attain progressive chain exchanges. FT-IR analysis was performed to analyze the curing of epoxy vitrimer biocomposites, where the diminution of oxirane ring $\left(915 \mathrm{~cm}^{-1}\right)$ was observed and denoted a complete curing of epoxy (Figure 1(b)) [34]. The epoxy curing was noted at the interval of every one hour using FT-IR analysis, and it was found that the curing was complete after 5 h (see Figure S1).

3.2. Thermomechanical Properties. Thermomechanical properties of AC-epoxy vitrimer biocomposites were investigated through a thermomechanical analyzer, which allows the determination of their $T_{\mathrm{g}}$ and dynamic mechanical perfor- mance. The determined $T_{\mathrm{g}}$ for the pristine epoxy vitrimer and the AC-epoxy vitrimer biocomposites loaded with different percentages of AC filler are tabulated in Table 1 (see Figure S2). From the observed results, material EP-1 denotes the lowest $T_{\mathrm{g}}$ among the investigated epoxy samples. A reduction in $T_{\mathrm{g}}$ was observed for all biocomposites, which could be due to the free volume space between matrix and nanofillers [35], and thus enhances the chain mobility helpful to achieve low-temperature self-healing properties. However, further addition of filler leads to slight increase in $T_{\mathrm{g}}$, which could be due to agglomeration of nanofillers in epoxy matrix $[36,37]$.

Storage modulus and loss modulus of the pristine epoxy vitrimer and AC-epoxy vitrimer biocomposites were observed to understand the temperature-dependent viscoelasticity 
TABLE 2: Dynamic properties of epoxy for epoxy and biocomposite vitrimers.

\begin{tabular}{lcccccccc}
\hline Samples & $\begin{array}{c}\text { Storage } \\
\text { modulus } \\
(\mathrm{GPa})\end{array}$ & $\begin{array}{c}\text { Flexural } \\
\text { strength } \\
(\mathrm{MPa})\end{array}$ & $\begin{array}{c}\text { Flexural } \\
\text { strain at } \\
\text { break } \\
(\mathrm{mm} / \mathrm{mm})\end{array}$ & $\begin{array}{c}\text { Flexural } \\
\text { modulus } \\
(\mathrm{GPa})\end{array}$ & $\begin{array}{c}\text { Activation } \\
\text { energy } \\
\left(E_{a}\right)(\mathrm{kJ} / \mathrm{mol})\end{array}$ & $\begin{array}{c}\text { Topology } \\
\text { transition } \\
\text { temperature } \\
\left(T_{v}\right)\left({ }^{\circ} \mathrm{C}\right)\end{array}$ & $\begin{array}{c}\text { Before } \\
\text { healing } \\
(\mathrm{GPa})\end{array}$ & $\begin{array}{c}\text { After } \\
\text { healing } \\
(\mathrm{GPa}) \\
1^{\text {st }}\end{array}$ \\
\hline EP-p & 39.7 & 18.0 & 0.06 & 32.1 & 59 & 19 & 32.1 & 23.4 \\
$2^{\text {nd }}$
\end{tabular}

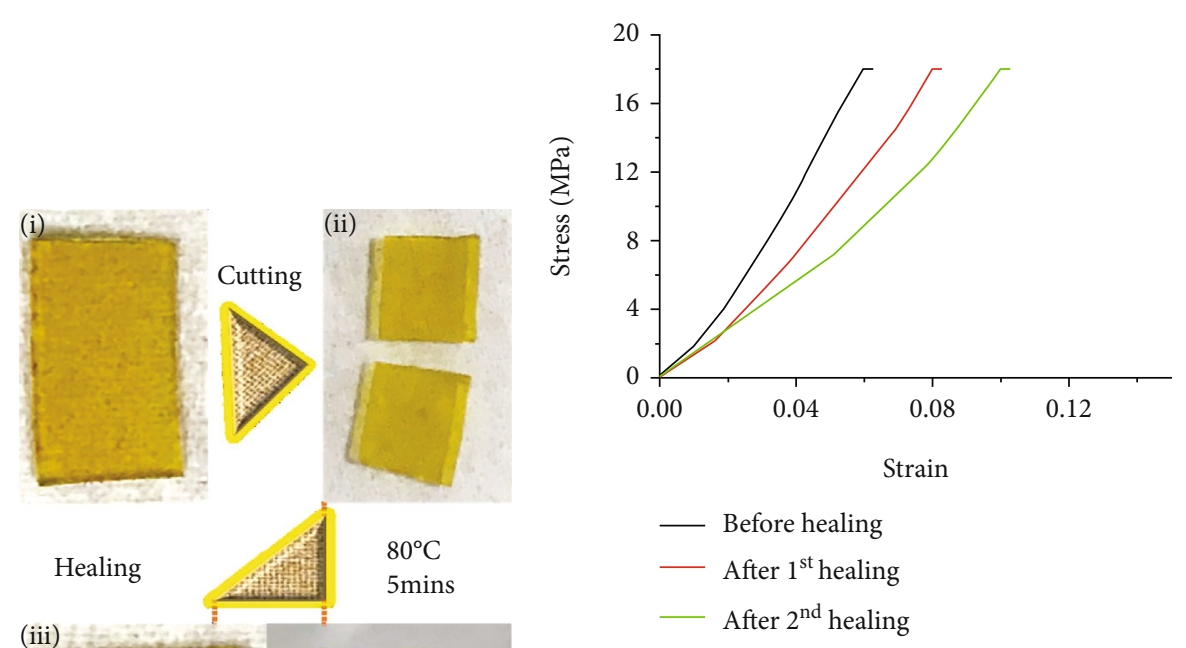

(b)

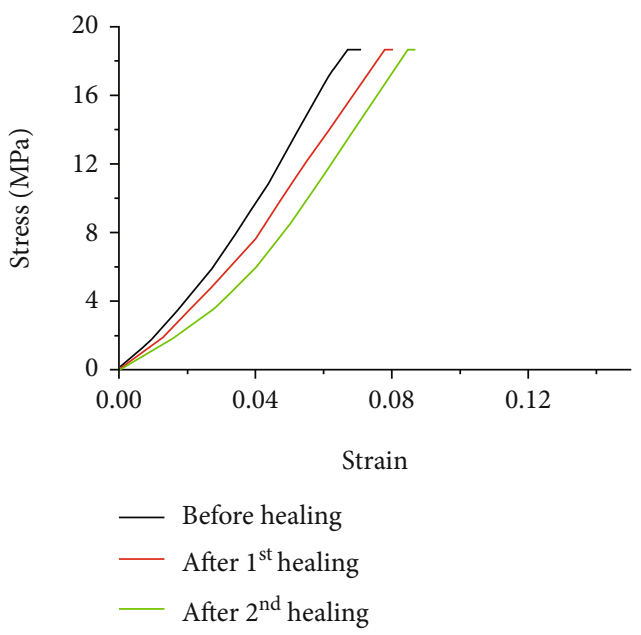

(a)

(c)

FIGURE 3: (a) Self-healing of epoxy vitrimer: (i) pristine EP-p, (ii) cut into two pieces, and (iii) rejoined. Healing efficiency of vitrimer was calculated via the stress-strain relationship for (b) EP-p and (c) EP-1.

(Figures 2(a) and 2(b)). It was found that biocomposites with $1 \mathrm{wt} \%$ of AC exhibit a higher storage modulus than pristine epoxy vitrimer. EP-1 demonstrates a higher storage modulus (Table 2) due to the presence of activated carbon, where matrix-interlocked fillers have restricted the chain exchanges at lower temperature. However, EP-1 has availed a faster reduction in viscoelasticity (above $T_{\mathrm{g}}$ ), where the addition of AC has reduced the glass transition temperature $\left(T_{\mathrm{g}}\right)$ of the epoxy vitrimer (due to filler and matrix free volume space). During the period of temperature change, the performed material EP-1 has exhibited a faster decline in storage and loss modulus than the pristine sample; thus, performed material viscoelasticity (storage and loss modulus) was entirely dependent with the solid to rubbery phase change temperature (i.e., glass transition temperature) [4].

A three-point bending test using the force ramp mode at $40^{\circ} \mathrm{C}$ was performed for calculating the stress-strain behavior of the prepared samples. The pristine and biocomposite vitrimers demonstrate a similar stress-strain behavior (Figure 2(c)). However, a lower strain at break and a higher flexural modulus of AC-epoxy vitrimer biocomposite compared to pristine epoxy vitrimer denote 
the stiffness increment as well as high bending resistance upon the incorporation of AC. A 35\% increment in flexural modulus was obtained with the addition of AC nanofillers (Table 2).

3.3. Stress Relaxation. Stress relaxation experiments were performed for the EP-p and EP-1 at different temperatures $\left(60^{\circ} \mathrm{C}, 70^{\circ} \mathrm{C}\right.$, and $\left.80^{\circ} \mathrm{C}\right)$; hence, resulted relaxation times $(\mathrm{EP}-\mathrm{p}=112.8 \mathrm{~s}, 40.8 \mathrm{~s}$, and $34 \mathrm{~s} ; \mathrm{EP}-1=234 \mathrm{~s}, 129.6 \mathrm{~s}$, and $46.2 \mathrm{~s}$, respectively) were plotted in the Arrhenius equation (Figures S3 and S4) to identify the activation energy of the pristine epoxy vitrimer and its biocomposites (SI) [38].

The investigated relaxation time for EP-p was comparatively lower than that for EP-1. This could be due to the presence of activated carbon, which has restricted the chain mobility and increased the viscosity of epoxy vitrimer. However, free volume formation between filler and matrix was found to be the key component for reduction in glass transition temperature [35].

3.4. Self-Healing Mechanical Properties. The performed first healing of pristine epoxy vitrimer and AC-epoxy vitrimer biocomposite demonstrates efficient self-healing via disulfide exchanges (Figure 3(a); video 1). The specimen was cut into two pieces with the help of a razor blade, both the pieces were immediately kept together at $70^{\circ} \mathrm{C}$ for $5 \mathrm{~min}$, and the healing efficiency was evaluated from the stress-strain relationship. The activated carbon involving EP-1 demonstrates self-healing at $70^{\circ} \mathrm{C}$, owing to their low glass transition temperature, as low $T_{\mathrm{g}}$ is helpful to achieve the S-S bond rearrangement. Disulfide-mediated radical exchange is the key factor for achieving the self-healing behavior for vitrimeric materials [39], as conventional epoxy specimen devoid of 2aminophenyl disulfide does not show the healing properties. The healing efficiency was evaluated through flexural studies (Figures 3(b) and 3(c)), where healed pristine epoxy vitrimer and AC-epoxy vitrimer biocomposites demonstrate healing efficiency $73 \%$ and $85 \%$, respectively, after the first cycle. Then, the performed second healing demonstrates a $60 \%$ and $78 \%$ healing; a reduction in healing efficiency after each cycle was observed. However, material flexural strength was quite similar after every healing cycle, whereas a change in flexural modulus and strain at break was observed.

\section{Conclusion}

It is concluded that activated carbon from sugarcane bagasse could be an effective filler to achieve sustainable epoxy vitrimer biocomposite. The high surface area of activated carbon in AC-epoxy vitrimer biocomposite makes them capable to achieve progressive chain exchanges. The disulfide exchanges promoted temperature-dependent self-healing observed at $80^{\circ} \mathrm{C}$ for $5 \mathrm{~min}$ in pristine epoxy vitrimer, and the material had demonstrated a lower temperature self-healing at $70^{\circ} \mathrm{C}$ for $5 \mathrm{~min}$ upon the addition of activated carbon. Healing efficiency evaluated via flexural studies highlighted a prominent recovery in vitrimer biocomposites with $1 \mathrm{wt} \%$ of $\mathrm{AC}$ (EP-1), where $85 \%$ and $70 \%$ efficiency was exhibited after two consecutive healings. In the future, biocomposite vitri- mer study would be helpful to envisage efficient vitrimer composite materials for real-time applications with sustainable properties.

\section{Data Availability}

The data used to support the findings of this study are available from the corresponding author upon request.

\section{Conflicts of Interest}

The authors declare no conflict of interest.

\section{Acknowledgments}

We gratefully acknowledge the financial support from the Science and Engineering Research Board (SERB-DST), Government of India (Grant No. ECR/2016/001355).

\section{Supplementary Materials}

Table 1: different nanocomposite percentage prepared with an addition of dispersed solutions (AC). Figure S1: FT-IR results for EP-pristine curing with respect to time. Figure S2: glass transition temperatures for different percentages of activated carbon involved epoxy vitrimer (1-5). Figure S3: Arrhenius equation plotted graph $(\ln (\tau *)$ vs. 1/T) for EPp. Figure S4: Arrhenius equation plotted graph $(\ln (\tau *)$ vs. 1/T) for EP-1. (Supplementary Materials)

\section{References}

[1] K. Varaprasad, M. Pariguana, G. M. Raghavendra, T. Jayaramudu, and E. R. Sadiku, "Development of biodegradable metaloxide/polymer nanocomposite films based on poly$\varepsilon$-caprolactone and terephthalic acid," Materials Science and Engineering: C, vol. 70, Part 1, pp. 85-93, 2017.

[2] L. Guadagno, M. Raimondo, C. Naddeo, P. Longo, and A. Mariconda, "Self-healing materials for structural applications," Polymer Engineering and Science, vol. 54, no. 4, pp. 777-784, 2014.

[3] M. Raimondo and L. Guadagno, "Healing efficiency of epoxybased materials for structural applications," Polymer Composites, vol. 34, no. 9, pp. 1525-1532, 2013.

[4] L. Guadagno, L. Vertuccio, C. Naddeo et al., "Self-healing epoxy nanocomposites via reversible hydrogen bonding," Composites. Part B, Engineering, vol. 157, pp. 1-13, 2019.

[5] L. Guadagno, L. Vertuccio, C. Naddeo et al., "Reversible selfhealing carbon-based nanocomposites for structural applications," Polymers (Basel), vol. 11, no. 5, p. 903, 2019.

[6] B. Krishnakumar, R. V. S. P. Sanka, W. H. Binder, V. Parthasarthy, S. Rana, and N. Karak, "Vitrimers: associative dynamic covalent adaptive networks in thermoset polymers," Chemical Engineering Journal, vol. 385, p. 123820, 2019.

[7] A. M. Peterson, R. E. Jensen, and G. R. Palmese, "Thermoreversible and remendable glass-polymer interface for fiberreinforced composites," Composites Science and Technology, vol. 71, no. 5, pp. 586-592, 2011.

[8] D. Montarnal, M. Capelot, F. Tournilhac, and L. Leibler, "Silica-like malleable materials from permanent organic networks," Science, vol. 334, no. 6058, pp. 965-968, 2011. 
[9] H. Zhang and $\mathrm{X} . \mathrm{Xu}$, "Improving the transesterification and electrical conductivity of vitrimers by doping with conductive polymer wrapped carbon nanotubes," Composites. Part A, Applied Science and Manufacturing, vol. 99, pp. 15-22, 2017.

[10] D. J. Fortman, J. P. Brutman, C. J. Cramer, M. A. Hillmyer, and W. R. Dichtel, "Mechanically activated, catalyst-free polyhydroxyurethane vitrimers," Journal of the American Chemical Society, vol. 137, no. 44, pp. 14019-14022, 2015.

[11] W. Denissen, G. Rivero, R. Nicolaÿ, L. Leibler, J. M. Winne, and F. E. Du Prez, "Vinylogous urethane vitrimers," Advanced Functional Materials, vol. 25, no. 16, pp. 2451-2457, 2015.

[12] Y. Xu and D. Chen, "A novel self-healing polyurethane based on disulfide bonds," Macromolecular Chemistry and Physics, vol. 217, no. 10, pp. 1191-1196, 2016.

[13] J. Han, T. Liu, C. Hao, S. Zhang, B. Guo, and J. Zhang, “A catalyst-free epoxy vitrimer system based on multifunctional hyperbranched polymer," Macromolecules, vol. 51, no. 17, pp. 6789-6799, 2018.

[14] Z. Yang, Q. Wang, and T. Wang, "Dual-triggered and thermally reconfigurable shape memory graphene-vitrimer composites," ACS Applied Materials \& Interfaces, vol. 8, no. 33, pp. 21691-21699, 2016.

[15] Y. Zhu, F. Gao, J. Zhong, L. Shen, and Y. Lin, "Renewable castor oil and DL-limonene derived fully bio-based vinylogous urethane vitrimers," European Polymer Journal, vol. 135, p. $109865,2020$.

[16] H. Zheng, Q. Liu, X. Lei, Y. Chen, B. Zhang, and Q. Zhang, “A conjugation polyimine vitrimer: fabrication and performance," Journal of Polymer Science Part A: Polymer Chemistry, vol. 56, no. 22, pp. 2531-2538, 2018.

[17] A. Ruiz de Luzuriaga, R. Martin, N. Markaide et al., "Epoxy resin with exchangeable disulfide crosslinks to obtain reprocessable, repairable and recyclable fiber-reinforced thermoset composites," Materials Horizons, vol. 3, no. 3, pp. 241-247, 2016.

[18] B. Krishnakumar, M. Singh, V. Parthasarthy et al., "Disulfide exchange assisted self-healing epoxy/PDMS/graphene oxide nanocomposites," Nanoscale Advances, vol. 2, no. 7, pp. 2726-2730, 2020.

[19] J. Tang, L. Wan, Y. Zhou, H. Pan, and F. Huang, "Strong and efficient self-healing adhesives based on dynamic quaternization cross-links," Journal of Materials Chemistry A, vol. 5, no. 40, pp. 21169-21177, 2017.

[20] Q. Chen, Y. Li, Y. Yang et al., "Durable liquid-crystalline vitrimer actuators," Chemical Science, vol. 10, no. 10, pp. 30253030, 2019.

[21] X. Hu, M. Fan, B. F. Towler, M. Radosz, D. A. Bell, and O. A. Plumb, "Hydrogen adsorption and storage," in Coal Gasification and Its Applications, pp. 157-245, Elsevier Inc., 2011.

[22] S. Dhers, G. Vantomme, and L. Avérous, "A fully bio-based polyimine vitrimer derived from fructose," Green Chemistry, vol. 21, no. 7, pp. 1596-1601, 2019.

[23] Z. Ma, Y. Wang, J. Zhu, J. Yu, and Z. Hu, "Bio-based epoxy vitrimers: reprocessibility, controllable shape memory, and degradability," Journal of Polymer Science Part A: Polymer Chemistry, vol. 55, no. 10, pp. 1790-1799, 2017.

[24] Z. Guo, B. Liu, L. Zhou et al., "Preparation of environmentally friendly bio-based vitrimers from vanillin derivatives by introducing two types of dynamic covalent C N and S-S bonds," Polymer, vol. 197, p. 122483, 2020.
[25] R. P. Babu, K. O'Connor, and R. Seeram, "Current progress on bio-based polymers and their future trends," Progress in Biomaterials, vol. 2, no. 1, p. 8, 2013.

[26] X. Yang, L. Guo, X. Xu, S. Shang, and H. Liu, "A fully bio-based epoxy vitrimer: self-healing, triple-shape memory and reprocessing triggered by dynamic covalent bond exchange," Materials and Design, vol. 186, p. 108248, 2020.

[27] P. Kasemsiri, N. Lorwanishpaisarn, U. Pongsa, and S. Ando, "Reconfigurable shape memory and self-welding properties of epoxy phenolic novolac/cashew nut shell liquid composites reinforced with carbon nanotubes," Polymers, vol. 10, no. 5, p. 482, 2018.

[28] W. Zhao, Z. Feng, Z. Liang et al., "Vitrimer-cellulose paper composites: a new class of strong, smart, green, and sustainable materials," ACS Applied Materials \& Interfaces, vol. 11, no. 39, pp. 36090-36099, 2019.

[29] D. Bose, S. Sridharan, H. Dhawan, P. Vijay, and M. Gopinath, "Biomass derived activated carbon cathode performance for sustainable power generation from microbial fuel cells," Fuel, vol. 236, pp. 325-337, 2019.

[30] M. Pawlyta, J. N. Rouzaud, and S. Duber, "Raman microspectroscopy characterization of carbon blacks: spectral analysis and structural information," Carbon, vol. 84, pp. 479-490, 2015.

[31] A. Omri and M. Benzina, "Characterization of activated carbon prepared from a new raw lignocellulosic material : Ziziphus spina-christi seeds," Journal de la Société Chimique de Tunisie, vol. 14, pp. 175-183, 2012.

[32] Y. Soo, N. Chada, M. Beckner, J. Romanos, J. Burress, and P. Pfeifer, "Adsorbed methane film properties in nanoporous carbon monoliths," Proceedings of the APS March Meeting Abstracts, vol. 2013, article M38.001, 2013.

[33] M. K. Nazal, "An overview of carbon-based materials for the removal of pharmaceutical active compounds," in CarbonBased Material for Environmental Protection and Remediation, M. Bartoli, M. Frediani, and L. Rosi, Eds., IntechOpen, Rijeka, 2020.

[34] L. Guadagno, L. Vertuccio, A. Sorrentino et al., "Mechanical and barrier properties of epoxy resin filled with multi-walled carbon nanotubes," Carbon, vol. 47, no. 10, pp. 2419-2430, 2009.

[35] C. Park, J. Jung, and G. J. Yun, “Thermomechanical properties of mineralized nitrogen-doped carbon nanotube/polymer nanocomposites by molecular dynamics simulations," Composites. Part B, Engineering, vol. 161, pp. 639-650, 2019.

[36] G. B. Olowojoba, S. Kopsidas, S. Eslava et al., "A facile way to produce epoxy nanocomposites having excellent thermal conductivity with low contents of reduced graphene oxide," Journal of Materials Science, vol. 52, no. 12, pp. 7323-7344, 2017.

[37] N. G. Sahoo, S. Rana, J. W. Cho, L. Li, and S. H. Chan, "Polymer nanocomposites based on functionalized carbon nanotubes," Progress in Polymer Science, vol. 35, no. 7, pp. 837-867, 2010.

[38] B. Krishnakumar, R. V. S. P. Sanka, W. Binder, Y. C. Jung, V. Michaud, and N. Sahoo, Submission Files Included in This PDF Submission Files Not Included in This PDF Research Data Related to This Submission Composites Part B : Engineering Dear, S. Rana, Ed., PhD University of Petroleum \& Energy Studies (UPES), 2020.

[39] B. Krishnakumar, R. V. S. Prasanna Sanka, W. H. Binder et al., "Catalyst free self-healable vitrimer/graphene oxide nanocomposites," Composites. Part B, Engineering, vol. 184, p. 107647, 2020. 